\title{
Novel set of real-time PCR primers for simultaneous detection of Liberibacter species associated with citrus Huanglongbing
}

\author{
Ingrid Georgina Orce ${ }^{1}$, Lorena Noelia Sendín, María Rosa Marano², Adrián Alberto Vojnov³ , Atilio Pedro Castagnaroㄹ, María Paula \\ Filippone $^{1 *}$
}

\begin{abstract}
${ }^{1}$ Obispo Colombres Agro-Industrial Experimental Station/ National Council for Scientific and Technical Research Institute of Agro-Industrial Technology of Northwestern Argentina, Av. William Cross 3150, C.P. T4101XAC - Las Talitas, Tucumán - Argentina.

${ }^{2}$ National University of Rosario/Faculty of Biochemistry and Pharmacy - Institute of Molecular and Cellular Biology of Rosario, Suipacha 590, S2002LRK - Rosario - Argentina. 3nstitute of Science and Technology "Dr. Cesar Milstein"/ CONICET, Saladillo 2468, C.P. C1440FFX - Ciudad

Autónoma de Buenos Aires - Argentina.

*Corresponding author <paulafilippone@eeaoc.org.ar>
\end{abstract}

Edited by: Luís Eduardo Aranha Camargo

Received December 19, 2013

Accepted September 07, 2014
ABSTRACT: Huanglongbing (HLB), a devastating citrus disease caused by the bacterium "Candidatus Liberibacter spp.", is now responsible for significant economic losses worldwide. Yet, no effective disease control has been found, and the non-cultivability of the bacterium has severely hampered studies on the pathogen. The 16S rDNA gene is a well-characterized sequence, essential for cell survival, and is used for bacterial identification or assignment of close relationships at the genus and species levels. Quantitative Real-Time PCR (qPCR) assays based on 16S rDNA genes are widely used in the detection of "Ca. Liberibacter spp." in multiplex reactions. We have developed for the first time a set of qPCR primers based on the conserved 16S rDNA gene, which specifically and simultaneously detects in a singleplex reaction, all three bacterial species associated with HLB, and can differentiate $\mathrm{Ca}$. Liberibacter asiaticus or africanus from americanus by their characteristic melting curves. The assay is very sensitive, and it was possible to amplify expected DNA fragments with an efficiency of $98 \%$ using the Syber Green system and a $\mathrm{Ct}$ value lower than tested methods for HLB diagnosis. The application of this fast, simple and efficient detection methodology could also be important in the detection of all species of HLB-associated Liberibacters and could contribute to early pathogen detection, a crucial step in the development of preventive strategies aimed at avoiding the dissemination of this devastating disease in HLB-free areas.

Keywords: Candidatus Liberibacter spp., Syber Green qPCR, Argentina, greening, pathogen detection

\section{Introduction}

Huanglongbing (HLB) is the most serious citrus disease that gives rise to global economic losses (Gottwald et al., 2007). Its causal agent is a Gram negative and phloem-inhabiting bacterium, "Candidatus Liberibacter spp." (Jagoueix et al., 1994). For many years, two species have been associated with HLB: "Ca. Liberibacter asiaticus" (Las), first known in Asia and later found in South, North and Central America, and "Ca. Liberibacter africanus" (Laf), only reported in Africa (Gottwald, 2010). However, in 2004, a third bacterial species was detected in Brazil, "Ca. Liberibacter americanus" (Lam), (Teixeira et al., 2005). Liberibacter can be transmitted by grafting, dodder or two insect vectors: Diaphorina citri for Las and Lam, and Trioza erytreae for Laf (Bové, 2006).

HLB is a significant threat to all regions not yet infested. In Argentina, D. citri was first reported in the province of Entre Ríos (32 $02^{\prime} 52^{\prime \prime} \mathrm{S}$ and $\left.60^{\circ} 16^{\prime} 52^{\prime \prime} \mathrm{O}\right)$ (Vaccaro, 1994) and later found in Salta $\left(23^{\circ} 21^{\prime} 28^{\prime \prime} \mathrm{S}\right.$ and $\left.64^{\circ} 09^{\prime} 63^{\prime \prime} \mathrm{W}\right)$ and Jujuy $\left(23^{\circ} 45^{\prime} \mathrm{S}\right.$ and $\left.65^{\circ} 30^{\prime} \mathrm{O}\right)$ (Augier et al., 2006). In June 2012, positive detection of HLB was confirmed in backyard trees in Misiones $\left(26^{\circ} 55^{\prime} \mathrm{S}\right.$ and $\left.54^{\circ} 31^{\prime} \mathrm{O}\right)$, located in the northeast of Argentina, but no HLB has been detected yet in commercial citrus groves in those regions (Dr. Outi, personal communication, 2013). No direct disease control is available, and the little knowledge we have of the disease, combined with the aggressive infection behavior and difficulties to control the bacteria, makes tree protection the most important management measure.

HLB diagnosis based on disease symptoms is difficult because of similarities to nutritional deficiencies (Bové, 2006). Microscopy, serology and DNA-DNA hybridization used to detect the pathogens (Bové, 2006; Villechanoux et al., 1990) are either time consuming or lacking in sensitivity. Methods based on PCR have been widely used to detect HLB-associated Liberibacter, mainly based on the $16 \mathrm{~S}$ rDNA and the beta operon sequences (Hocquellet et al., 1999; Hung et al., 1999; Jagoueix et al., 1996; Teixeira et al., 2005), and several real-time quantitative $\mathrm{PCR}$ assays ( $\mathrm{qPCR}$ ) have been designed to detect and quantify low Liberibacter titers, both in plants (Li et al., 2006; Teixeira et al., 2008) and insects (Manjunath et al., 2008).

With the aim of detecting simultaneously the three Liberibacter species associated with HLB, we have designed a qPCR primer set that amplifies a region of the $16 \mathrm{~S}$ rDNA gene, considering the high degree of conservation of this gene for its importance in the functioning of cells (Clarridge, 2004). This primer set is as sensitive or even more sensitive than other reported primers, which makes this methodology a simple and efficient tool for the early detection of the pathogen and the development of management strategies to avoid the rapid dissemination of HLB. 


\section{Materials and Methods}

\section{DNA sample and plasmid preparation}

The pGEM-T Easy vector containing the $16 \mathrm{~S}$ rDNA sequence from Las, Lam and Laf was used to construct a standard curve for the different sets of qPCR-primers. Quantification of the plasmid DNA based on the copy number $(\mathrm{CN})$ of the target gene was determined as previously described by Wang et al. (2006). The plasmid solution was serially diluted from $10^{8} \mathrm{CN}$ to $1 \mathrm{CN}$.

DNA samples of symptomatic leaves from 65 citrus trees and 40 insects were collected as microbial-free, noninfectious DNA samples. The Las/Lam-infected leaves were from Sao Paulo, Brazil $\left(23^{\circ} 30^{\prime} \mathrm{S}\right.$ and $\left.46^{\circ} 37^{\prime} \mathrm{O}\right)$, and the Laf-infected leaves were from Pretoria, South Africa (25 $43^{\prime} 32^{\prime \prime} \mathrm{S}$ and $\left.28^{\circ} 14^{\prime} 38^{\prime \prime} \mathrm{E}\right)$.

As a negative control for the PCR and qPCR assays, total DNA was extracted from the midribs (about $250 \mathrm{mg}$ ) of healthy greenhouse-grown sweet orange (Citrus sinensis L.) trees (about five years old) by using the CTAB method (Murray and Thompson, 1980) and suspended in $100 \mu \mathrm{L}$ of water. As a non-template control (NTC), water was included.

\section{Primer design and validation of primer-specificity}

A new set of qPCR primer pair, named p3G, was designed based on $16 \mathrm{~S}$ rDNA sequences of " $\mathrm{Ca}$. Liberibacter spp." obtained from the DNA database GenBank (accession numbers: NC_020549 of Las, EU921621 of Laf and AY742824 of Lam). Multiple sequence alignments were performed using DNAMAN software and from these analyses primers were designed for a specific sequence region in order to amplify the DNA from all three species of different sizes. The p3G primers were empirically designed in this region using the software Primer3 (http:// frodo.wi.mit.edu/). The sequences of forward primer $\mathrm{f}$ p3G and reverse primer r-p3G were

5'-CTTATCACCGGCAGTCCCTATAAAG-3' and 5'-CAGCTCGTGTCGTGAGATGTTG-3', respectively, and led to an amplicon of $122 \mathrm{bp}$ for Las, $121 \mathrm{bp}$ for Laf and $105 \mathrm{bp}$ for Lam.

Analyses for the detection of $\mathrm{Ca}$. L. solanacearum (Lso, accession numbers EU834130.1) were carried out by in silico PCR using the program http://insilico.ehu.es/PCR/.

To make sure that the designed primers were unique to "Ca. Liberibacter spp.", a search was performed against available microbial sequences in the GenBank and in silico PCR (http://insilico.ehu.es/PCR/). The specificity of primer pairs were also PCR-evaluated with DNA prepared from a number of citrus-related pathogens, including Xanthomonas citri subsp. citri, the causal agent of citrus canker; Xylella fastidiosa strain 9a5c, the causal agent of citrus variegated chlorosis, and Guirnardia citricarpa, the causal agent of black spot. Genomic DNA from pure cultures of other bacterial species like Enterococcus and citrus endophytes, Burkholderia sp. and Methylobacterium sp., were also included. Twenty samples of citrus leaves ( 4 of $C$. sinensis and 16 of $C$. limon) collected in non-infected areas in Tucumán $\left(27^{\circ} 0^{\prime} 0^{\prime \prime} \mathrm{S}, 65^{\circ} 30^{\prime} 0^{\prime \prime} \mathrm{W}\right)$, Argentina, were tested with the $\mathrm{p} 3 \mathrm{G}$ primers.

\section{Conventional PCR and Real-time PCR for the new p3G primers}

To determine optimal annealing temperatures, a conventional PCR experiment was conducted by using a MyCycler thermal-cycler with a temperature gradient heating block. Primer annealing temperatures were set from $58{ }^{\circ} \mathrm{C}$ to $72{ }^{\circ} \mathrm{C}$. The PCR reaction was performed in a total volume of $25 \mathrm{uL}$ containing $1 \times$ master mix, 0.4 $\mathrm{uM}$ of each primer (f-p3G and r-p3G) and $500 \mathrm{ng}$ of DNA template.

For real-time PCR, SYBR Green (SG) systems were used (SG qPCR). Real-time PCR assays with the new sets of primers were performed by using a Miniopticom Realtime PCR. All reactions were generated in triplicate and each run contained one negative (-DNA, HLB-free citrus DNA) and one positive DNA control (plasmid DNA). PCR amplification conditions were $95^{\circ} \mathrm{C}$ for $10 \mathrm{~min}$ followed by 40 cycles of $95^{\circ} \mathrm{C}$ for $30 \mathrm{~s}$ and, $70{ }^{\circ} \mathrm{C}$ for $45 \mathrm{~s}$. The reactions were generated using a total volume of $25 \mathrm{uL}$ containing $1 \times$ master mix (iQ SYBR Green, BioRad), 0.4 $\mathrm{uM}$ of each primer (f-p3G and r-p3G) and the appropriate amount of DNA template. Data were analyzed using CFX Manager Software Version 2.1 from BioRad.

\section{Sensitivity assay of the qPCR method}

To compare the assay sensitivity of the $\mathrm{qPCR}$, different HLB-detection PCR reactions were chosen. For a SYBR Green real-time PCR comparison, the primer pair f-rplLAs/r-rplLAs for "Ca. Liberibacter asiaticus", previously published by Teixeira et al. (2008) was used. The standard curve for rplLas was constructed using ten-fold serial dilutions of plasmid DNA containing the sequence of the rplKAJL-rpoBC gene cluster ( $\beta$-operon) from Las. A Taqman based real-time PCR assay was performed using an HLBasp 16S rDNA primer-probe set as previously described (Li et al., 2006). To compare the different qPCR systems, optimization and standardization were carried out with ten-fold dilutions of total DNA samples obtained from field-grown plants infected with Las.

\section{Results}

\section{Novel qPCR primers designed to detect HLB Liberibacter species}

The new set of primers p3G was empirically designed based on the 16S rDNA sequences of "Ca. Liberibacter spp." (GenBank accession numbers: NC_020549 of Las, EU921621 of Laf and AY742824 of Lam). A specific sequence region was retrieved by aligning and comparing the various bacterial 16S rDNA sequences and a new set of primers was designed. Primer pair p3G is specific to Liberibacter and recognizes all three known HLB-associated species. Amplification products expected for Las, Laf and Lam are 122 bp, 121 bp and 105 bp, respectively. A BLAST search against all available microbial sequence da- 
tabases at NCBI and an in silico PCR amplification experiment did not identify any additional homologous DNA sequences, suggesting high specificity of the designed primers (Figure 1). Even though these primers were specifically designed for HLB "Ca. Liberibacters spp.", p3G was able to amplify "Ca. Liberibacter solanacearum". In silico PCR performed with this bacterium gave the expected fragment (121 bp) with one mismatch at the beginning of the sequence, thus indicating the potential broad application of the $\mathrm{p} 3 \mathrm{G}$ primers.

\section{Optimizations of SG qPCR conditions and standard curve}

To attain an efficient and solid SG qPCR, the optimization of the primer's annealing temperature is important for determining high endpoint fluorescence and low Ct values. To determine optimal annealing temperatures, conventional PCR experiments were conducted by using plasmid DNA containing the $16 \mathrm{~S}$ rDNA gene sequence from Las. Annealing test temperatures were set from $62{ }^{\circ} \mathrm{C}$ to $72{ }^{\circ} \mathrm{C}$. Distinct and single DNA bands were amplified at annealing temperatures between $65^{\circ} \mathrm{C}$ and $70{ }^{\circ} \mathrm{C}$ (Figure 2). The higher temperature of $70{ }^{\circ} \mathrm{C}$ was considered to be the optimal annealing temperature for the $\mathrm{qPCR}$ primers, since it allowed for higher stringency of the PCR reaction.

The SG qPCR yielded positive amplification results only for plasmid DNA corresponding to Las, Lam or Laf with Ct values between 12 and 14. In the absence of DNA (NTC) or with DNA from healthy sweet orange, no Ct values were obtained. Melt-curve analysis showed that samples detected by SG qPCR were Liberibacter-specific amplicons with a melting peak at $82{ }^{\circ} \mathrm{C}$ for Lam and 83 ${ }^{\circ} \mathrm{C}$ for Las and Laf (Figure 3).

Ten-fold serial dilution series of the plasmid pGEM$\mathrm{T}$ Easy vector containing the $16 \mathrm{~S}$ rDNA gene sequence from either Las, Lam or Laf ranging from $10^{8}$ to $1 \mathrm{CN}$ $\mathrm{uL}^{-1}$, were used to make a standard curve with the p3G primers. DNA amplification was carried out using three replicates for each dilution tested. The standard curve obtained for Las had an average slope value of 3.370, indicating an efficiency of the PCR of $98 \%$. Similar results were obtained when standard curves were made for Lam and Laf. The detection limit for all three Liberibacters was equivalent to ten copies of $16 \mathrm{~S}$ rDNA. A linear relationship was observed between $\mathrm{Ct}$ values and the log concentrations of recombinant plasmid DNA (Figure 4).
Quantification of Liberibacter species in plant and insect samples by using $\mathrm{p} 3 \mathrm{G}$ primers

Positive DNA microbial-free, non-infectious DNA samples of leaves from 65 citrus trees and 40 insects were checked and species were identified by conventional PCR (data not shown) by using established protocols (Jagoueix et al., 1996; Teixeira et al., 2005). Next, the population of each Liberibacter was quantified by SG qPCR using the p3G primer set. Quantification of Liberibacter in target samples was performed as an indirect measurement of $\mathrm{CN}$ of the $16 \mathrm{~S}$ rDNA inserts deduced from the standard curve.

Out of 65 vegetal samples tested positive by qPCR for Liberibacter, 30 were positive for Las, 20 were positive for Lam, 13 samples tested positive for both species and only two were positive for Laf, which corresponded to the Laf positive control used in the assay. All Ct values of positive DNA leaf samples were between 14 and 24 (Table 1). Where a mix of Las and Lam was present in DNA samples, Ct values between 14 and 20 were observed (Table 1). When DNA samples extracted from insects were evaluated, 27 samples were positive for Las and 13 were positive for Lam. The Ct value was between 20 and 26 for both, Las and Lam pathogens. No discrepancy was observed between the results from real-time PCR with those obtained with conventional PCR (data not shown). The copy number of $16 \mathrm{~S}$ rDNA obtained with these Ct values in DNA samples varied from $10^{2}$ to $10^{6}$ CN (Table 1).

\section{Specificity of SG qPCR assay for the detection of "Ca. Liberibacter spp."}

The p3G set of primers amplified the specific target from DNA extracts of HLB infected plants with an optimal temperature of $70{ }^{\circ} \mathrm{C}$, without any amplification of negative bacterial controls and NTC. The primer pair p3G was specific to Las, Lam and Laf, and did not cross-react with endophytes commonly resident in citrus or other citrus pathogens including Xylella fastidiosa, Xanthomonas citri subsp. citri or the fungus Guirnardia citricarpa. Additionally, as expected these primers did not cross-react with other bacterial species like Enterococcus sp., isolated from the soil of sugarcane fields (Table 1), nor amplified samples of citrus leaves collected in non-infected growth areas in Tucumán, Argentina.

\footnotetext{
Las CTTATCACOGGCAGTCCCTATAAAGTNCCCAACATCTAGGTAAAAACCTAAACTTGATGGCAACTAGAGGCAGGGGTTGCGCTCGTTGCGGGACTTAACCCAACATCTCACGACACGAGCTG Lam CTTATCACCGGCAGTCCCTATAAAGTTCCCAACTT . . . . . . A. . . . . . . . TGATGGCAAATATAGGCAGGGGTTGCGCTCGTTGCGGGACTTAACCCAACATCTCACGACACGAGCTG Laf CTTATCACCGGCAGTCCCTATAAAGTACCCAACATCTAGATAAAA. TCTAAACTTGATGGCAACTAGAGGTAGGGGTTGCGCTCGTTGCGGGACTTAACCCAACATCTCACGACACGAGCTG Lso ATTATCACCGGCAGTCCCTATAAAGTACCCAACATCTAGATAAAA.TCTAAACTTGATGGCAACTAGAGGTAGGGGTTGCGCTCGTTGCGGGACTTAACCCAACATCTCACGACACGAGCTG p3G CTTATCACCGGCAGTCCCTATAAAG CAACATCTCACGACACGAGCTG
}

Figure 1 - Sequences of p3G qPCR primers for amplification of 16S rDNA of "Ca. Liberibacter spp." associated with citrus Huanglongbing and "Ca. Liberibacter solanacearum", the causal agent of diseases in Solanaceous plants. Las: "Ca. L. asiaticus", Lam: "Ca. L. americanus", Laf: "Ca. L. africanus", Lso: Ca. L. solanacearum, p3G: primer sequence, left: p3G-f, right: p3G-r. 


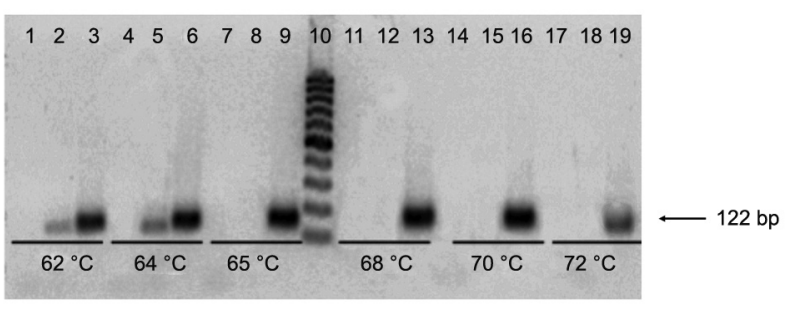

Temperature $\left({ }^{\circ} \mathrm{C}\right)$

Figure 2 - Optimization of annealing temperature for $\mathrm{p} 3 \mathrm{G}$ primers setting from $62{ }^{\circ} \mathrm{C}$ to $72{ }^{\circ} \mathrm{C}$. Line 10: Cien Marker (Biodynamics). Lines 1, 4, 7, 11, 14 and 17: non-template control (NTC). Lines 2, $5,8,12,15$ and 18: DNA from healthy sweet orange. Lines 3, 6, 9, 13, 16 and 19: positive control for "Ca. L. asiaticus".
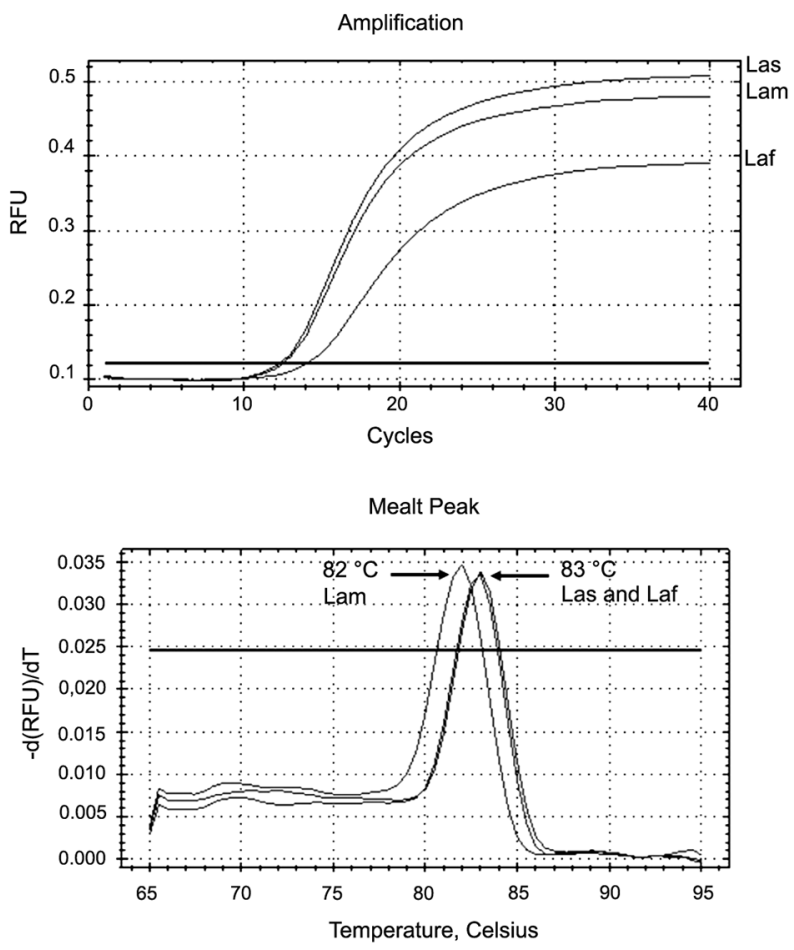

Figure 3 - SYBR Green quantitative PCR amplification curves and melting curves with primers $\mathrm{p} 3 \mathrm{G}$ for detection of "Ca. Liberibacter spp." in DNA samples of Liberibacters (Las: "Ca. L. asiaticus", Lam: "Ca. L. americanus" or Laf: "Ca. L. africanus"). Melting curve peak observed was $82^{\circ} \mathrm{C}$ for Lam and $83^{\circ} \mathrm{C}$ for Las and Laf.

\section{Comparison of sensitivity between PCR diagnostic methods}

The sensitivity of the SG qPCR assay developed in this study was compared to a certain number of previously established protocols. For this purpose, the $\beta$-operon primer set $\mathrm{f}$-rplLAs/r-rplLAs was selected for

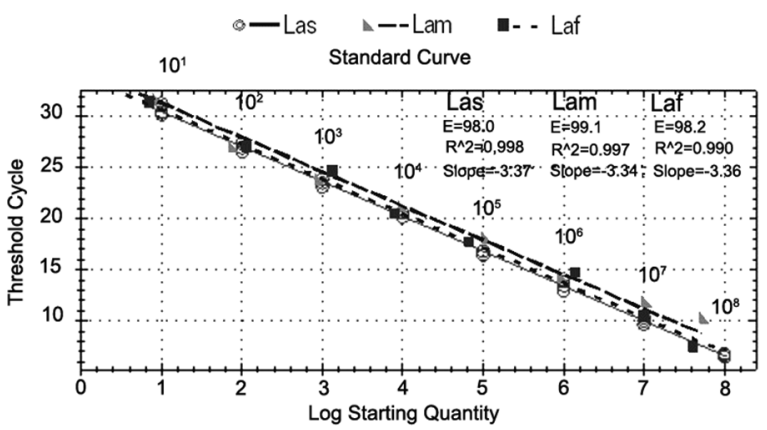

Figure 4 - Standard curve obtained with p3G primers using tenfold serial dilution ranging from $10^{8}$ to 1 copy number (CN) for the pGEM-T Easy vector containing 16S rDNA sequence from " $\mathrm{Ca}$. L. asiaticus" (Las), "Ca. L. americanus" (Lam) and "Ca. L. africanus" (Laf).

Las as described by Teixeira et al. (2008). The standard curve for rplLas was made by using ten-fold serial dilutions of plasmid DNA containing the sequence of the $r p l K A J L$-rpoBC gene cluster ( $\beta$-operon) from Las. The efficiency of the PCR reaction was $110 \%$ for Las with a detection limit of $10 \mathrm{CN}$ (Figure 5). When comparing both primer sets in SG qPCR assays, rplLas and p3G had the same detection limit. Both primer sets succeeded in detecting $10 \mathrm{CN}$ with an efficiency of $98 \%$ and $110 \%$ for $\mathrm{p} 3 \mathrm{G}$ and rplLas, respectively. However, the lowest $\mathrm{Ct}$ was observed for the $\mathrm{p} 3 \mathrm{G}$ primers when the same copy number of targeted DNA was compared (Figure 5). For $10^{8} \mathrm{CN}$ the $\mathrm{Ct}$ value for $\mathrm{p} 3 \mathrm{G}$ was 7 , whereas the $\mathrm{Ct}$ value for the rplLas primers was 13.

In vegetal samples, the detection limit was $10 \mathrm{CN}$ for both, p3G and rplLas primers with a Ct value of 33 and 35, respectively. The PCR efficiency was $103.3 \%$ for rplLas primers and $98 \%$, for p3G primers (Figure 6). The Ct values obtained with vegetal samples correlates with the Ct value observed for plasmid DNA. To further evaluate the p3G assay, another comparison was made against a detection method based on 16S rDNA amplification; this time the TaqMan system was applied by using a primer-probe set previously reported by Li et al. (2006). Vegetal samples containing DNA templates ranging from $10^{5}$ to $1 \mathrm{CN}$ had Ct values between 23 and 38 . The efficiency of the PCR reaction was $98.2 \%$ for Las and the detection limit of TaqMan PCR for HLB pathogens was therefore equal to 10 copies. Figure 6 shows curves obtained with one of the plant samples, named AS13.

\section{Discussion}

To prevent the outbreak and spreading of HLBassociated Liberibacter species in unaffected citrus production areas, it is necessary to have sensitive and reliable diagnostic methods for the early detection of the pathogen. This is particularly critical in areas where 
Table 1 - Specificity of SYBR Green quantitative PCR assays for "Candidatus Liberibacter spp." in 21 of 105 analyzed DNA samples.

\begin{tabular}{|c|c|c|c|c|c|c|}
\hline \multirow{2}{*}{ Samples } & \multirow{2}{*}{ Host } & \multirow{2}{*}{ Origin } & \multicolumn{3}{|c|}{ Ct Values with $\mathrm{p} 3 \mathrm{G}$ primers: } & \multirow{2}{*}{$\begin{array}{l}\text { Copy Number of target } \\
\text { 16S rDNA uL }{ }^{-1}\end{array}$} \\
\hline & & & Las & Lam & Laf & \\
\hline Ca. L. asiaticus 101 & Insect & Brazil & 20 & - & - & $10^{4}$ \\
\hline Ca. L. asiaticus 105 & Insect & Brazil & 24 & - & - & $10^{3}$ \\
\hline Ca. L. americanus 120 & Insect & Brazil & - & 26 & - & $10^{2}$ \\
\hline Ca. L. americanus 121 & Insect & Brazil & - & 24 & - & $10^{3}$ \\
\hline Ca. L. asiaticus 330 & Citrus sp. & Brazil & 21 & - & - & $10^{4}$ \\
\hline Ca. L. asiaticus 331 & Citrus sp. & Brazil & 18 & - & - & $10^{5}$ \\
\hline Ca. L. asiaticus 332 & Citrus sp. & Brazil & 20 & - & - & $10^{4}$ \\
\hline Ca. L. asiaticus 333 & Citrus sp. & Brazil & 14 & - & - & $10^{6}$ \\
\hline Ca. L. asiaticus 334 & Citrus sp. & Brazil & 17 & - & - & $10^{5}$ \\
\hline Ca. L. americanus 430 & Citrus sp. & Brazil & - & 18 & - & $10^{5}$ \\
\hline Ca. L. americanus 431 & Citrus sp. & Brazil & - & 17 & - & $10^{5}$ \\
\hline Ca. L. americanus 432 & Citrus sp. & Brazil & - & 21 & - & $10^{4}$ \\
\hline Ca. L. americanus 433 & Citrus sp. & Brazil & - & 18 & - & $10^{5}$ \\
\hline Ca. L. americanus 434 & Citrus sp. & Brazil & - & 20 & - & $10^{4}$ \\
\hline Ca. L. americanus/Ca. L. asiaticus 530 & Citrus sp. & Brazil & 20 & 20 & - & $10^{4}$ \\
\hline Ca. L. americanus/ Ca. L. asiaticus 531 & Citrus sp. & Brazil & 18 & 18 & - & $10^{5}$ \\
\hline Ca. L. americanus/ Ca. L. asiaticus 532 & Citrus sp. & Brazil & 17 & 17 & - & $10^{5}$ \\
\hline Ca. L. americanus/ Ca. L. asiaticus 533 & Citrus sp. & Brazil & 14 & 14 & - & $10^{6}$ \\
\hline Ca. L. americanus/ Ca. L. asiaticus 534 & Citrus sp. & Brazil & 15 & 15 & - & $10^{6}$ \\
\hline Ca. L. africanus 701 & Citrus sp. & Africa & & - & 23 & $10^{3}$ \\
\hline Ca. L. africanus 705 & Citrus sp. & Africa & - & - & 24 & $10^{3}$ \\
\hline Xanthomonas citri subsp. citri & Citrus sp. & Argentina & - & - & - & - \\
\hline Xylella fastidiosa & Citrus sp. & Argentina & - & - & - & - \\
\hline Guignardia citricarpa & Citrus sp. & Argentina & - & - & - & - \\
\hline Enteroccocus & & Argentina & - & - & - & - \\
\hline $\begin{array}{l}\text { Endophytes citrus bacterial } \\
\text { Burkholderia sp. } \\
\text { Methylobacterium sp. }\end{array}$ & Citrus sp. & Argentina & - & - & - & - \\
\hline
\end{tabular}

Las: “Ca. L. asiaticus”; Lam: “Ca. L. americanus”; Laf: “Ca. L. africanus”.
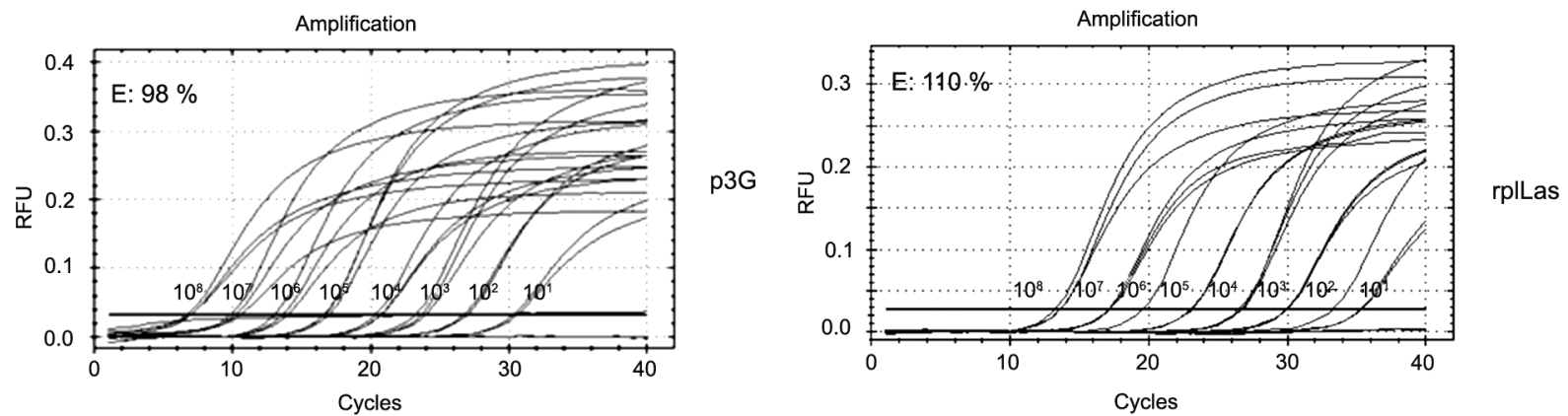

Figure 5 - Comparing sensitivity of SYBR Green quantitative PCR assays with p3G primers (left) and rplL as primers (right) for detection of "Ca. L. asiaticus" using ten-fold serial dilutions of plasmid DNA.

psyllids are present and HLB has not yet been reported, as in the northwest of Argentina.

The rapid expansion of HLB in Brazil and Florida are examples where the confirmation of the disease occurred much later than the infection by the pathogen (Coletta-Filho et al., 2004; Manjunath et al., 2008), which clearly attests that the plant had been infected for a long period of time when disease symp- toms appeared. It is rather difficult to diagnose HLB on the basis of disease symptoms, and when it happens, it is too late to prevent it from spreading. In areas where the HLB pathogen is unknown or undetected, a strategy that allows for both early detection of any Liberibacter species and low inoculum loads is necessary in order to detect the disease in time. Thus, it is imperative to be able to confirm the presence of 

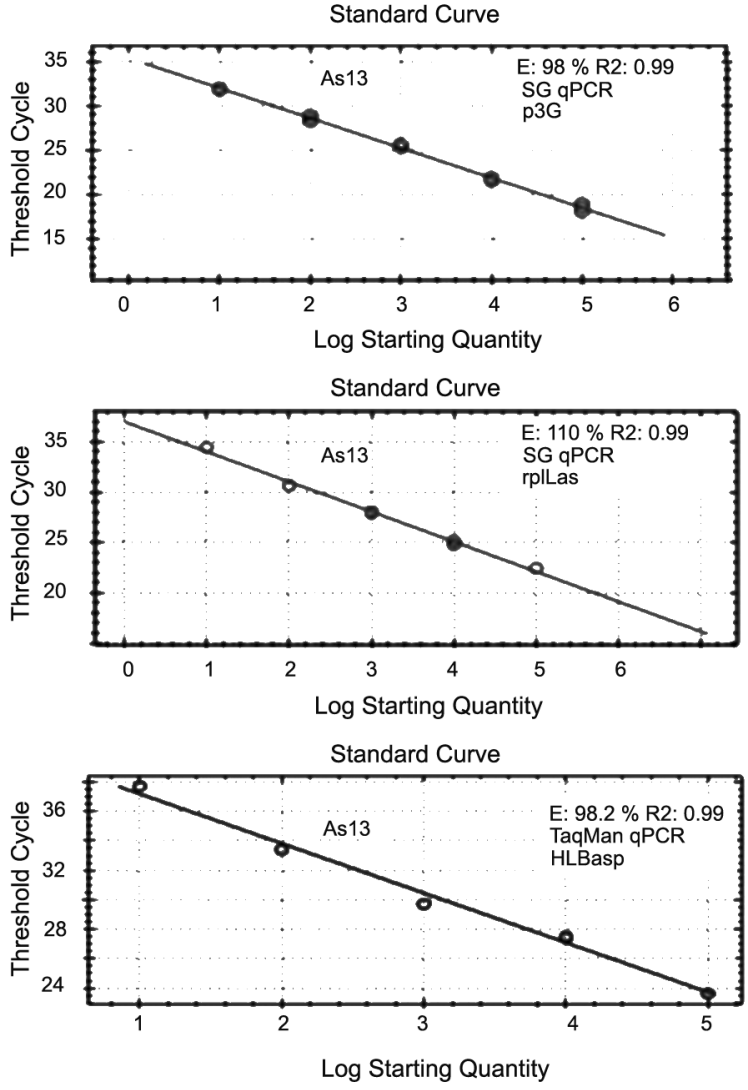

Figure 6 - Comparison of qPCR systems for HLB diagnostic. The standard curves for SYBR Green (p3G and rplLas, upper and middle, respectively) and TaqMan qPCR assays (HLBasp, down) were obtained by using as a template a ten-fold serial dilution from a quantified DNA extracted from a vegetal sample infected with "Ca. L. asiaticus", (named AS13), ranging from $10^{5}$ to 1 copy number (CN).

the pathogen in order to act as quickly as possible, and then additional measures can be taken to identify the species present.

Recently, new diagnosis systems such as biosensors and optical sensing techniques have been developed. However, the most sensitive and rapid method for detecting the pathogen is to use various PCR-based molecular techniques. This method is currently being used in most laboratories for HLB diagnosis in different parts of the world. Continuous improvements have been introduced in these diagnostic strategies, particularly to make possible detection of more than one Liberibacter species. For this purpose, Li et al. (2006) have developed a multiplex real-time PCR (TaqMan) assay using a probe-primer set for detection of the three known species of Liberibacter causing HLB. This test uses a 16S rDNA-based TaqMan probe and a set of three different forward primers for the detection of the three different species of Liberibacter and one common reverse primer. This set has been successfully applied in the detection, identification and quantification of Las in host plants of citrus (Li et al., 2009; Tatineni et al., 2008) and in the psyllid vector (Manjunath et al., 2008).

In order to simplify methods currently used in the detection of HLB-associated pathogens, a region of the $16 \mathrm{~S}$ rDNA gene has been used to design a new set of primers; they hybridize perfectly to the genome of all three species of Liberibacter causing HLB in a singleplex real-time PCR reaction. The $16 \mathrm{~S}$ rDNA sequences are highly conserved among the species of Liberibacter but variation between them is sufficient to prompt designing primers capable of detecting and identifying the bacterium in PCR assays (Coletta-Filho et al., 2005; Jagoueix et al., 1996; Teixeira et al., 2005). The gene is large enough to provide distinctly and statistically valid measurements as it has sufficient interspecific polymorphisms of the 16S rDNA gene.

The sensitivity of the qPCR assay development in this study was tested against a standard qPCR methodology and the Ct values of the p3G primers were compared with PCR-primers targeting the $16 \mathrm{~S}$ rDNA gene $(\mathrm{Li}$ et al., 2006) or the $\beta$-operon region (Teixeira et al., 2005) of "Ca. Liberibacter spp.". qPCR protocols tested showed the same detection limit, ten copies, but the $\mathrm{Ct}$ value obtained with the p3G primers was lower than that obtained by the other methods tested. Kim and Wang (2009) indicate that $\mathrm{Ca}$. Liberibacter asiaticus contains three copies of $16 \mathrm{~S}$ rDNA and, compared to qPCR assays targeting $\beta$-operon, a $16 \mathrm{~S}$ rDNA based qPCR assay which is likely to be more sensitive, due to its higher copy number per genome. This could help to define diagnostic situations where a very high $\mathrm{Ct}$ is obtained, close to the safety limit.

Ananthakrishnan et al. (2013) have reported the design of a single pair of degenerate primer-probes targeting the rpoB gene of Liberibacter enabling the detection of "Ca. Liberibacter spp." at the genus level in one PCR reaction. In a similar way, like the method developed for the rpoB gene, the $\mathrm{p} 3 \mathrm{G}$ primers described in this analysis detect all three Liberibacter species associated with HLB with high sensibility and specificity. Both methods can confirm whether Libericabter is present in a plant or insect sample; however, with the p3G primers Las/Laf from Lam samples can be differentiated by their characteristic melting curves. This is especially interesting in the continents of North and South America where two forms of HLB have been reported, Las and Lam (Teixeira et al., 2005; Teixeira et al., 2008).

If necessary, the Liberibacter species present in a sample could be determined by an electrophoresis by using a DNA analyzer system like a sequencer; the amplification produces three different sizes of DNA for each Liberibacter species. In contrast, this is not possible for the rpo assay because the size of the amplified fragment is the same for all three species of Liberibacter. Further- 
more, the comparison of the $16 \mathrm{~S}$ rDNA gene sequences allows for differentiation between organisms at the genus level across all major phyla of bacteria, in addition to classifying strains at multiple levels, including at specie and subspecie level (Clarridge, 2004). The degree of conservation is assumed to result from the importance of the $16 \mathrm{~S}$ rDNA as a critical component of cell function, a fact which contrasts with other genes which can usually tolerate mutations with more frequency since they may affect structures not as unique and essential as rDNA (Clarridge, 2004).

Although it is possible to design three fluorescent probes to detect the three species of Liberibacter in the same reaction tube using the $\mathrm{p} 3 \mathrm{G}$ assay, our main goal was to design a method that is sensitive, simple and low-cost for diagnosis. The addition of more probes to the reaction tube could not only interfere and hamper the efficiency of the test but would also increase the cost of reaction per sample. To avoid this, a representative region of the $16 \mathrm{~S}$ rDNA gene was chosen; this area allowed to design of highly specific primers, without decreasing the sensitivity and specificity, as well as producing a new cost-effective tool for HLB diagnosis.

Reaction in silico was performed using the $16 \mathrm{~S}$ rDNA sequence from "Ca. Liberibacter solanacearum", which is the causal agent of diseases of high economic impact on solanaceous crops (mainly potatoes and tomatoes) and carrots (Munyaneza et al., 2012). Thus, the p3G primers designed for HLB Liberibacter detection were expected to amplify the expected fragment (121 bp) with one mismatch at the $5^{\prime}$ end, showing the possible broad application of these primers.

The singleplex assay was designed using the $\mathrm{p} 3 \mathrm{G}$ primers hybridizing to a very conserved sequence of the Liberibacter genomes associated with HLB. This strategy could be of importance for the detection of new species which cause the diseases, especially after two HLB causing species were identified in Brazil, one of which had never been reported previously. The present analysis offers an efficient technique for the diagnosis of HLB which, combined with a thoroughly designed sample testing program, would help to prevent the outbreak and spread of this devastating disease in major citrus production areas not yet affected.

\section{Acknowledgments}

This project was partially supported by the EEAOC Citrus Program. MRM, AAV, APC and MPF are members of the CONICET. LNS and IGO are CONICET fellows. We especially thank Dr H. Coletta-Filho /Centro Apta de Citricultura Sylvio Moreira, SP, Brazil), Dr. D. Teixeira (FUNDECITRUS, SP, Brazil) for providing us the $16 \mathrm{~S}$ rDNA and rplLas plasmid DNA and HLB positive samples and Dr Welin (EEAOC, Argentina) for the critical reading of this manuscript and for reviewing the English version of the manuscript.

\section{References}

Ananthakrishnan, G.; Hu, H.; Brlansky, R. 2013. Development and applications of primers and probe for genus specific detection of 'Candidatus Liberibacter species' by real-time PCR. Plant Disease 97: 1235-1243.

Augier, L.; Gastaminza, G.; Lizondo, M.; Argañaraz, M.; Willink, E. 2006. Presence of Diaphorina citri (Hemiptera: Psyllidae) in Northwestern Argentina (NOA). Revista de la Sociedad Entomológica Argentina 65: 67-68 (in Spanish).

Bové, J.M. 2006. Huanglongbing: a destructive, newly-emerging, century-old disease of citrus. Journal of Plant Pathology 88: 7-37.

Clarridge, J.E. 2004. Impact of $16 \mathrm{~S}$ rRNA gene sequence analysis for identification of bacteria on clinical microbiology and infectious diseases. Clinical Microbiology Reviews 17: 840-862.

Coletta-Filho, H.; Takita, M.; Targon, M.; Machado, M. 2005. Analysis of $16 \mathrm{~S}$ rDNA sequences from citrus huanglongbing bacteria reveal a different "Ca. Liberibacter" strain associated with citrus disease in Sao Paulo. Plant Disease 89: 848-852.

Coletta-Filho, H.; Targon, M.; Takita, M. 2004. First report of the causal agent of Huanglongbing ("Candidatus Liberibacter asiaticus") in Brazil. Plant Disease 88: 1382.

Gottwald, T.R.; Da Graça, J.V.; Bassanezi, R.B. 2007. Citrus huanglongbing: the pathogen and its impact. Plant Health Progress 6.

Gottwald, T.R. 2010. Current epidemiological understanding of citrus Huanglongbing. Annual Review of Phytopathology 48: 119-139.

Hocquellet, A.; Toorawa, P.; Bové, J.M.; Garnier, M. 1999. Detection and identification of the two "Candidatus Liberobacter

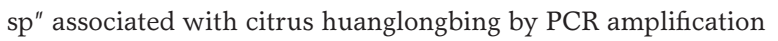
of ribosomal protein genes of the beta operon. Molecular and Cellular Probes 13: 373-379.

Hung, T.; Wu, N.M.; Su, H. 1999. Development of a rapid method for the diagnosis of citrus greening disease using the polymerase chain reaction. Journal of Phytopathology 147: 599-604.

Jagoueix, S.; Bove, J.M.; Garnier, M. 1994. The phloem-limited bacterium of greening disease of citrus is a member of the $\alpha$ subdivision of the Proteobacteria. International Journal of Systematic Bacteriology 44: 379-386.

Jagoueix, S.; Bové, J.M.; Garnier, M. 1996. PCR detection of the two "Candidatus liberobacter species" associated with greening disease of citrus. Molecular and Cellular Probes 10: 43-50.

Kim, J.; Wang, N. 2009. Characterization of copy numbers of $16 \mathrm{~S}$ rDNA and 16S rRNA of Candidatus Liberibacter asiaticus and the implication in detection in planta using quantitative PCR. BioMed Central Research Notes 2: 37.

Li, W.; Hartung, J.S.; Levy, L. 2006. Quantitative real-time PCR for detection and identification of Candidatus Liberibacter species associated with citrus huanglongbing. Journal of Microbiological Methods 66: 104-115.

Li, W.; Levy, L.; Hartung, J.S. 2009. Quantitative distribution of 'Candidatus Liberibacter asiaticus' in citrus plants with citrus Huanglongbing. Phytopathology 99: 139-144.

Manjunath, K.; Halbert, S.; Ramadugu, C.; Webb, S.; Lee, R. 2008. Detection of 'Candidatus Liberibacter asiaticus' in Diaphorina citri and its importance in the management of Citrus huanglongbing in Florida. Phytopathology 98: 387-396. 
Munyaneza, J.E.; Sengoda, V.G.; Stegmark, R.; Arvidsson, A.K.; Anderbrant, O.; Yuvaraj, J.K. 2012. First Report of "Candidatus Liberibacter solanacearum" associated with Psyllid-affected carrots in Sweden. Plant Disease 96: 453.

Murray, M.; Thompson, W.F. 1980. Rapid isolation of high molecular weight plant DNA. Nucleic Acids Research 8: 43214326.

Tatineni, S.; Sagaram, U.S.; Gowda, S. 2008. In planta distribution of 'Candidatus Liberibacter asiaticus' as revealed by polymerase chain reaction (PCR) and real-time PCR. Phytopathology 98: 592-599.

Teixeira, D.C.; Ayres, A.J.; Kitajima, E.W.; Tanaka, F.A.O.; Danet, J.L.; Jagoueix-Eveillard, S.; Saillard, C.; Bove, J.M. 2005. First report of a huanglongbing-like disease of citrus in São Paulo state, Brazil, and association of a new liberibacter species, Candidatus Liberibacter americanus, with the disease. Plant Disease 89: 107.

Teixeira, D.C.; Saillard, C.; Couture, C.; Martins, E.C.; Wulff, N.A.; Jagoueix-Eveillard, S.; Yamamoto, P.T.; Ayres, A.J.; Bove, J.M. 2008. Distribution and quantification of Candidatus Liberibacter americanus, agent of huanglongbing disease of citrus in São Paulo state, Brasil, in leaves of an affected sweet orange tree as determined by PCR. Molecular and Cellular Probes 22: 139-150.
Vaccaro, N.C. 1994. Behavior and dissemination of "sharpshooter of Citrus" Diaphorina citri (Homoptera-Diaphoridae) in the citrus area of Entre Rios. In: Carpeta de información citrícola. v. 2. Sección G (27). EEA/INTA, Concordia, Argentina (in Spanish).

Villechanoux, S.; Garnier, M.; Bové, J.M. 1990. Purification of the bacterium-like organism associated with greening disease of citrus by immunoaffinity chromatography and monoclonal antibodies. Current Microbiology 21: 175-180.

Wang, Z.; Yin, Y.; Hu, H.; Yuan, Q.; Peng, G.; Xia, Y. 2006. Development and application of molecular-based diagnosis for 'Candidatus Liberibacter asiaticus', the causal pathogen of citrus huanglongbing. Plant Pathology 55: 630-638. 